\title{
Effects of cycling alone or in a sheltered position on subsequent running performance during a triathlon
}

\author{
Christophe Hausswirth ${ }^{1}$, Didier Lehénaff ${ }^{1}$, Patrick Dréano ${ }^{2}$, and Kai Savonen ${ }^{3}$ \\ 1 - Laboratoire de Biomécanique et de Physiologie, Institut National du Sport et de L'Education \\ Physique, 75012 Paris, FRANCE;
}

2 - CREPS de Boulouris, Côte d'Azur, 83700 Saint-Raphaël, FRANCE;

3 - Institut des Sports de Vuokatti, 88615 Vuokatti Op, FINLAND

\begin{abstract}
Purpose: The purpose of this study was to compare the responses during a triathlon in which cycling was performed alone, as well as in a drafting position. Methods: Eight male triathletes of international level performed a sprint-distance triathlon $(0.75-\mathrm{km}$ swim, $20-\mathrm{km}$ bike, $5-\mathrm{km}$ run) on two different occasions, one completely alone (TA), the other as a drafter during the bike leg of the event (TD). The speed during drafted cycling remained at all times identical to the no-draft situation. Results: The results revealed that expiratory flow (VE), oxygen uptake $\left(\mathrm{VO}_{2}\right)$, heart rate $(\mathrm{HR})$, and blood lactate concentrations $\left(\left[\mathrm{La}^{-}\right]\right)$were significantly lower when drafting on the bike as opposed to biking alone (112.1 vs $162.2 \mathrm{~L} \cdot \mathrm{min}^{-1}, 55.2 \mathrm{vs} 64.2 \mathrm{~mL} \cdot \mathrm{min}^{-1} \cdot \mathrm{kg}^{-1}, 155 \mathrm{vs} 166.8$ beats $\bullet \mathrm{min}^{-1}$, and 4.0 vs $8.4 \mathrm{mmol} \cdot \mathrm{L}-$ 1 , respectively). The results also showed that running alter biking in a drafting situation (for similar bike speeds) significantly improved the running speed compared with that of the no-draft modality $\left(17.8\right.$ vs $\left.17.1 \mathrm{lcm} \cdot 11^{-1}\right)$. Furthermore, $\mathrm{VE}, \mathrm{VO}_{2}, \mathrm{HR}$, and [La] were significantly higher during TD run compared with TA run (161.6 vs $141.4 \mathrm{~L} \cdot \mathrm{min}^{-1}, 70.9$ vs $67.1 \mathrm{~mL} \cdot \mathrm{min}^{-1} \cdot \mathrm{kg}^{-1}, 175.3$ vs 167.98 beats $\bullet \mathrm{min}^{-1}$, and 8.1 vs $7.6 \mathrm{mmol} \bullet \mathrm{L}$ respectively). Conclusions: These results showed that drafting allows triathletes to save significantly on energy during the bike leg of a triathlon and creates the conditions for an improved running performance, with higher benefits for the strong runners.
\end{abstract}

Key Words: TRIATHLETES, DRAFTING POSITION, OXYGEN UPTAKE, PEDALING RATE, TELEMETRY

The growing success and impact of merging endurance sports such as triathlon raises renewed questions on the physiological characteristics and mechanisms regulating such a versatile sport in which prolonged exercise appears to activate various muscular groups in successive sequences. Among other areas of interest, the fast evolution of this sport with regard to its training approach, racing strategies, or race regulations calls for studies aimed at evaluating the new physiological and biomechanical constraints that competitors have to endure and overcome in their daily practice. As an example, one may assume that the present evolution of triathlon tending to systematize draft-legal races (group riding) during the bike leg of a triathlon (whereas until recently triathlon was considered as a pure individual effort) modifies the energy expenditure (EE) of biking and therefore incidentally alters the overall performance of the subsequent run.

The energy cost may be approached (in cycling, walking, or running) by adding aerodynamic and nonaerodynamic costs, as expressed by the following equation:

$$
\mathrm{EC}=\mathrm{ECa}+\mathrm{ECna} .
$$

Drafting has been studied in each of the three disciplines composing triathlon $(6,16,24,35)$ and has proven far more beneficial to tested subjects in cycling compared with swimming or running, as clearly demonstrated by, for instance, the reduction in HR when riding in a group $(9,16,17)$. In cycling, ECna is greatly reduced and most metabolic power is used to overcome air resistance. In fact, one may 
assume that $\mathrm{ECa} \mathrm{kV}(2)$ (where $\mathrm{k}$ is a constant factor and $\mathrm{V}$ is the velocity) and that ECna is the EE needed to overcome the gravity force and the inertia of the variations in velocity of the body gravity center (an insignificant factor in cycling, because body weight is carried by the bike). Therefore, it appears clearly that energy saved in cycling is largely de-pendent upon the reduction of factor $\mathrm{k}$, with $\mathrm{k}$ $\mathrm{Cx} \cdot \mathrm{Sp} \bullet(\rho / \eta)$ (where $\mathrm{Cx}$ is the aerodynamic coefficient, Sp the frontal projected surface of the moving object, $\rho$ the air density, and $\eta$ the resulting efficiency of locomotion).

Several studies have evidenced an increase in the energy cost of running at the end of a triathlon compared with a control run achieved at the same speed $(8,12)$. However, studies investigating the physiological responses of biking alone or in a group during the course of a triathlon have never been carried out to date.

The aims of the present study were: i) to verify the reduced EE of riding behind another cyclist during the bike leg of a triathlon in race environmental conditions; and ii) to compare the physiological differences (HR, oxygen uptake, and lactatemia) and the differences in performance between the proposed run sessions (drafted triathlon vs no-draft triathlon vs isolated run).

\section{MATERIALS AND METHODS}

Subjects. The subjects who participated in this study were eight male triathletes belonging to the French and Finnish national teams. They presented physiological profiles in accordance with their level of performance $\left(\mathrm{VO}_{2 \max }\right.$ between 70 and $\left.80 \mathrm{~mL}-\mathrm{min}^{-1}-\mathrm{kg}^{-1}\right)$. They were fully informed of the content and ramifications of the experiment. The subjects were selected on the basis of their performance time over the Olympic distance triathlon ( $1 \mathrm{~h} 55 \mathrm{~min} \pm 3.2$ ). To familiarize the triathletes with all cycling and running circuits of the experiment, a training camp was programmed $10 \mathrm{~d}$ before with a light training program. During the entire experimental procedure, the subjects had not performed any exhausting exercise in the $48 \mathrm{~h}$ preceding each test. All triathletes appeared to be extremely motivated, due to the fact that the experimental trials were conducted 2 wk before the Cleveland World championships. In that case, the precise order of the experiments did not affect the results of the study due to motor skills learning or a Jack of motivation. Mean age was $20.8 \pm 2.1 \mathrm{yr}$ (between 18 and $23 \mathrm{yr}$ of age). Mean body weight and height were $68 \pm 4.8 \mathrm{~kg}$ and $179 \pm 9.1 \mathrm{~cm}$, respectively. These data are in accordance with others recorded in previous studies $(17,21)$.

Protocol and experimental procedures. All experiments (Fig. 1) were carried out on the sites of the 1997 European triathlon championships (Vuokatti, Finland) in July 1996 and received financial and technical support from the French National Institute of Sport and Physical Education (I.N.S.E.P.), the Vuokatti Sports Institute, the European Triathlon Union, the Finnish Triathlon Association, the French Triathlon Federation, and the Finnish company Polar Electro OY. Outside air temperatures ranged from 19 to $25^{\circ} \mathrm{C}$. The weather conditions were exactly identical (no wind) during both triathlons and the $5-\mathrm{km}$ isolated run (IR). All triathletes first performed an IR test of $5000 \mathrm{~m}$ on a relatively flat course, alternating forest paths $(1 \mathrm{st} \mathrm{km})$, and asphalt roads $(4 \mathrm{~km})$. The course was marked every 500 $\mathrm{m}$ to record split times and average speeds. The two experimental triathlons that followed were performed over the Sprint distance $(0.75-\mathrm{km}$ swim, $20-\mathrm{km}$ bike, $5-\mathrm{km}$ run) with a $3-\mathrm{d}$ recovery between them. The swim was staged in a lake $\left(17--19^{\circ} \mathrm{C}\right)$ marked every $100 \mathrm{~m}$ with Bright buoys, and each triathlete had to wear his race wetsuit. The $20-\mathrm{km}$ road bike course was marked every kilometer to record split times and average speeds for each subject and included a slight uphill section at $\mathrm{km} 13$. The run used the course selected for the IR test. All triathletes had to perform both tests one by one; they always started with the no-draft triathlon (triathlon alone, TA), which they were instructed to complete as fast as possible. During the swim of the draft triathlon (TD), athletes had to respect their TA swim times, being informed at each buoy of their paces by visual and ring signals. During the bike leg of the TD, each triathlete drafted a professional road cyclist of comparable frontal projection, whose task was to respect an split times recorded during the TA by the triathlete they were sheltering Finally, the run section of the TD was left free, the only instruction given to the performing triathlete being to run as fast as possible during the entire $5000 \mathrm{~m}$. In addition, no feedback was given to the triathlete about his running velocity. He had to perform his run section alone without any outside 
information. During both triathlon tests athletes could drink $250 \mathrm{~mL}$ at each of the two transitions (swim-to-bike and bike-to-run).

Measurement of gas exchanges. Oxygen consomption $\left(\mathrm{VO}_{2}\right)$ and ventilation (VE) were recorded continuously for all bike and run sections by means of a gas exchange telemetric system (Cosmed K4, Milan, Italy). This system had previously been experimentally validated (13) in a protocol comparing it with a standard laboratory system (CPX, Medical Graphics, Saint-Paul, MN). The calculation of the energy cost of running $(\mathrm{Cr})$ is usually performed using the formula given by Di Prampero (7):

$$
\mathrm{Cr}\left(\mathrm{ml} \text { of } \mathrm{O}_{2} \cdot \mathrm{min}^{-1} \cdot \mathrm{km}^{-1}\right)=\frac{\dot{\mathrm{VO}} 2\left(\mathrm{ml} \text { of } \mathrm{O}_{2} \cdot \mathrm{min}^{-1} \cdot \mathrm{kg}^{-1}\right)-0.083}{\operatorname{Speed}\left(\mathrm{km} \cdot \mathrm{h}^{-1}\right)} \times 60
$$

where 0.083 (in ml-kg ${ }^{-1} \cdot \mathrm{s}^{-1}$ ) is the $\mathrm{VO}_{2}$ value corresponding to the y-intercept of the $\mathrm{V}_{2}$-speed relationship established in young male adults (19).

During the course of the experiment, the triathletes were followed at all times by a vehicle in which the receiving unit of the Cosmed $\mathrm{K} 4$ was positioned. The data were stored every $15 \mathrm{~s}$; furthermore, heart and pedaling rates were recorded by Polar Electro Cyclovantage computers (Kempele, Finland) positioned on each athlete and bike. All frequency meters were calibrated before the start of the experiment to integrate the body mass of the subjects in the calibration system determining instantaneous racing speeds.

Blood sampling. Capillary blood samples were collected at subjects' fingertips in $25-\mu \mathrm{L}$ heparinized capillary tubes after each test and at the end of the swim and bike legs of the experimental triathlons. Blood lactate concentration was then assayed by an enzymatic method (1).

Statistical analysis. The global statistical analysis to appreciate the evolution of all studied parameters in relation to the various moments and types of exercise identified (TA, TD, IR) was performed by means of a two-way ANOVA plan ( 2 X 3). The comparison of variables between the experimental conditions was conducted with Student' $\mathrm{s}$ t-test for paired samples. All values are expressed as mean SD. In all statistical tests the level of significance was set at $P<0.05$.

\section{RESULTS}

Performances. Swim times $\left(t_{s}\right)$ were $10 \min 07 \pm 25 \mathrm{~s}$ and $10 \min 15 \pm 22 \mathrm{~s}$ for TA and TD, respectively. HR values reached $168 \pm 7$ beats $\bullet \mathrm{min}^{-1}$ for TA and $166 \pm 11$ beats $\bullet \mathrm{min}^{-1}$ for TD. Post swim lactate values [La] were $8.4 \pm 0.5 \mathrm{mmol} \cdot \mathrm{L}^{-1}$ for TA and $8.1 \pm 0.7 \mathrm{mmol} \cdot \mathrm{L}^{-1}$ for TD. No significant difference between the two swim legs was recorded for any of the studied parameters $\left(t_{s}\right.$, $\mathrm{HR}, \mathrm{La})$. Performance in cycling and running is represented in Table 1: the increase in running time was $+1.8 \%$ for TD vs IR, and $+5.5 \%$ for TA vs IR.

\section{Ventilatory parameters and HR.}

i) Cycling: the ANOVA revealed a global effect of exercise mode $(P<0.01)$ on $\mathrm{VO}_{2}$ (Fig. 2A) and HR (Fig. 2B). Values arranged at every $4 \mathrm{~km}$ were significantly higher at all times for TA compared with TD, for both $\mathrm{VO}_{2}$ and $\mathrm{HR}$. Furthermore, mean values $\left(\mathrm{VO}_{2}, \mathrm{HR}\right)$ at $\mathrm{km} 8,12,16$, and 20 of the TD bike section were significantly lower than the mean initial values at $\mathrm{km} 4$. Overall mean values of $\mathrm{VO}_{2}$ and HR for the entire 20-km bike course of both triathlon trials are shown in Table 2. We noted a significant decrease for both $\mathrm{VO}_{2}$ and $\mathrm{HR}$ between TA and TD (-14\% and $-7 \%$, respectively). With regard to ventilation, mean bike VE values were significantly higher for TA compared with TD (Table 2). 


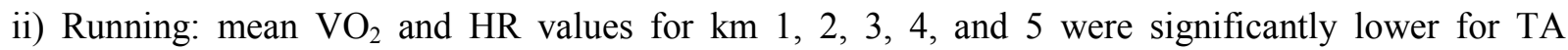
compared with TD $(P<0.01)$ (Fig. 3, A and B, respectively). Mean $\mathrm{VO}_{2}$ values for km 2 and 3 were also significantly higher $(P<0.01)$ for IR compared with the TD run. Mean HR were also higher for IR compared with TD for km $2(P<0.01), \mathrm{km} 3(P<0.05)$, and $\mathrm{km} 4(P<0.01) . \mathrm{VO}_{2}$ and $\mathrm{HR}$ values for the three runs (IR, TA, TD) are shown in Table 2 . The TA run generated values significantly lower $(P<0.01)$ than those collected during IR or TD. Moreover, mean $\mathrm{VO}_{2}$ and $\mathrm{HR}$ values were significantly lower for TD compared with IR ( $P<0.01$ and $P 0.05$, respectively) (Table 2$)$. In terms of percentages, $\mathrm{VO}_{2}$ was higher during IR than during TA $(+9.5 \%)$ and $\mathrm{TD}(+3.7 \%)$ and during TD compared with TA $(+6 \%)$. In the same manner, mean HR was higher during IR than during TA $(+4.9 \%)$ and TD $(+1.3 \%)$, and during TD compared with TA $(+3.9 \%)$. Finally, mean VE proved significantly higher during IR than during TA and TD $(P<0.01)$, and during TD compared with TA $(P$ $<0.01)$.

Blood lactate concentrations. A summary of all values is offered in Table 2. No significant difference was observed between the TD and TA swims. The comparison of bike lactate values clearly showed that TD [La'] was significantly lower than TA $\left[\mathrm{La}^{-}\right]\left(4 \mathrm{mmol} \cdot \mathrm{L}^{-1}\right.$ and $8.4 \mathrm{mmol} \cdot \mathrm{L}^{1}$, respectively, $P<$ $0.01)$. And only TD $\left[\mathrm{La}^{-}\right]$proved significantly higher than $\mathrm{IR}\left[\mathrm{La}^{-}\right](P<0.05)$ during the runs.

Pedaling rate. The results are illustrated in Figure 4. The pedaling rate was at all times higher during TD compared with TA $(P<0.01)$.

\section{DISCUSSION}

A number of studies have clearly demonstrated that drafting another cyclist of similar frontal projection contributes to bike performance optimization The first interesting finding in our study was the confirmation that drafting during the bike course of a triathlon lowered both EE, HR, and ventilation values, for a drafting distance of $0.2-0.5 \mathrm{~m}$ behind a lead cyclist. To our knowledge, drafting during the bike leg of a triathlon has not been scientifically documented. Therefore, our results need to be compared with those available in each of the three disciplines of triathlon. The present study has shown a global reduction in both $\mathrm{VO}_{2}(-14 \%)$, $\mathrm{HR}(-7.5 \%)$, and VE $(-30.8 \%)$ for the drafted bike leg (TD) and for an average speed of $39.5 \mathrm{~km} \cdot \mathrm{h}^{-}{ }^{1}$. McCole et al. (17) previously reported a higher reduction in $\mathrm{VO}_{2}(-26 \%)$ for a similar speed $\left(40 \mathrm{~km} \bullet \mathrm{h}-{ }^{1}\right)$. The apparent discrepancy between these results may be explained as follows: the bike leg of the proposed triathlons (TA and TD) was performed after an exhausting 750-m swim, as demonstrated by the high $\mathrm{VO}_{2}$ and $\mathrm{HR}$ values recorded during the first $4 \mathrm{~km}$ of the bike leg; we suggest that the triathlete was probably less efficient at drafting during the initial phase of the cycling section. (Fig. 2, A and B).

The lower EE recorded in the cycling trial during TD compared with TA may be linked to the observation that for the same horizontal speed, athletes develop a significantly $(P<0.01)$ higher freely chosen pedaling rate when biking in a drafting position $(95 \mathrm{rpm})$ than when biking alone $(89 \mathrm{rpm})$, as shown in Figure 4. A recent study showed that there was no significant difference between optimal and freely chosen pedaling rates in a 10-min bike exercise performed by regional level triathletes at $80 \%$ of their maximal aerobic power (36), the optimal pedaling rate being defined as the rate corresponding to the lowest force expressed on the pedals for a given power of exercise $(22,30)$. This reduction in the applied forces may be explained by a reduction in the activation of the vastus lateralis muscle (33) due to the decrease of wind resistance and connected to a reduction of the EE (10). In our study, the pedaling rate has increased significantly $(+6.3 \%)$ in the TD vs TA mode, whereas $\mathrm{VO}_{2}$ was reduced by a significant $-14 \%$. Therefore, it may be concluded that for the same horizontal speed of exercise, the higher pedaling rate observed may be associated with a reduction in the forces applied on the pedals, the latter eliciting the recruitment of a higher percentage of slow twitch fibers having a lower recruitment threshold (20), a larger oxidative capacity (23), and a better mechanical efficiency for contraction (5). Therefore, we may speculate that, in the TA mode the progressive recruitment of additional motor unit (MU) and/or the higher firing rate of recruited MU could compensate the deficit in contractility provoked by the alteration of fatigued MU. Though we had no electromyographical data at our disposai to confirm it, this hypothesis may well contribute to explaining the higher $\mathrm{VO}_{2}$ values 
observed in TA compared with TD for a same velocity. Moreover, the lower lactate values obtained after the TD bike $\left(4 \mathrm{mmol} \cdot \mathrm{L}^{-1}\right.$ vs $\left.8.4 \mathrm{mmol} \cdot \mathrm{L}^{-1}\right)$ confirm the idea that drafting causes the involvement of the metabolism in its aerobic-anaerobic component, thus enabling triathletes to save energy to continue their effort either biking (the same exercise) or a different one (running).

Because of the nature of outdoor biking and of the specific conditions related to its scientific observation, it remains very difficult to collect data to measure gas exchanges in general and $\mathrm{VO}_{2}$ in particular. Whereas most studies investigating outdoor cycling have only utilized speeds up to $25 \mathrm{~km} \bullet \mathrm{h}^{-}$ ${ }^{1}$ (3,26,32), only McCole et al. (17) studied cycling at higher speeds, when the power required to overcome air resistance exceeds that necessary to overcome both mechanical and rolling resistances. The lack of scientific data on outdoor biking led us to consider the data originating from running. Running economy, defined as a steady state of $\mathrm{VO}_{2}$ for a given speed, has indeed been well documented in the last $20 \mathrm{yr}(18,25)$. Though several researchers were able to characterize EE precisely $(8,15)$ and endocrinological modifications (12) incurred during a run performed immediately after a bike exercise, it had never been possible to estimate the influence of cycling in a drafting position on the subsequent running performance in terms of $\mathrm{VO}_{2}, \mathrm{HR}$, and $\left[\mathrm{La}^{-}\right]$. In our study, the best mean performance was obtained during the $5-\mathrm{km}$ IR. However, it is to be noted that the mean TD run performance was only $18 \mathrm{~s}$ slower than IR, that two triathletes were further able to perform even better during the TD run compared with IR ( $-1 \mathrm{~s}$ and $-3 \mathrm{~s}$, respectively), and finally that the smallest time differences noted between IR and TD run were achieved by triathletes particularly strong in the run. The improvement of the run Split times of all triathletes in TD compared with the run performed in TA was similarly observed with a population of skaters (28) who improved their times in an isolated sprint distance test, in short-track skating, performed immediately after a simulated 4-min drafting session behind a teammate. The results of this experiment suggested that short-track skaters who had the opportunity to draft off other skaters before a sprint event were able to perform better than when no draft opportunity was presented. Another study (25) evidenced an improvement in performances as a direct result of drafting; this author has shown that running in a drafting position could improve performance time up to one second per $400 \mathrm{~m}$, whereas the results of another study (16) estimated that $1.66 \mathrm{~s}$ could be gained per $400 \mathrm{~m}$ if runners were pacing in a sheltered position at a minimum of 24 $\mathrm{km} \cdot \mathrm{h}-{ }^{1}{ }^{\cdot}$ In the present study, the high $\left[\mathrm{La}^{-}\right]$at the beginning of TA run $\left(84 \mathrm{mmol} \cdot \mathrm{L}^{-1}\right)$ combined with high HR values are undoubtedly due to a higher state of muscular fatigue $(2,14)$ and invertedly proportional to the static and dynamic capacity of work $(11,14)$. Whereas an early study $(34)$ showed that metabolic acidosis, a critical index of muscular fatigue, reduced the activity of phosphofructokinase (PFK), the key glycolytic enzyme, a most recent study (31) suggests that despite the increasing acidosis and potentiel for inhibition, in vivo PFK activity was constant during electrical stimulation. The results showed also that although the concentrations of measured PFK deinhibitors or activators remained elevated, none increased during this period. The authors suggested that $\left[\mathrm{NH}_{4}{ }^{+}\right]$ accumulation assisted in counteracting the PFK inhibiting effect of increasing [ $\mathrm{Hl}$ and therefore the maintenance of glycolysis during muscle contractions. However, if a high lactate concentration is detrimental to a good performance in middle and long distance running, it seems that proton concentration ([Hl) in muscle fibers at the end of exercise plays ultimately a determinant role in the onset of muscle fatigue (29), because [ $\left.\mathrm{La}^{-}\right]$apparently influences solely [H1. In our investigation, TD run generated a higher $\left[\mathrm{La}^{-}\right]$than TA and isolated runs $(P<0.05)$; furthermore, this higher concentration corresponded to a lower level of performance in comparison with IR, though no significant statistical difference was observed. Moreover, the nonsignificant difference in the energy colt of running $(\mathrm{Cr})$ obtained during TA run and TD run $\left(235.1\right.$ and $238.7 \mathrm{~mL}$ of $0_{2} \bullet \mathrm{min}^{\bullet} \bullet$ respectively) could partly explain the non statistical difference in blood lactate concentrations obtained after TA run and TD run. As far as Cr for both TA and TD runs, the issue of why triathletes are running slower in TA run vs TD run is not fully understood. We suggest that the advantage is even psychological: by not having to exert as hard in the cycling phase, triathletes were probably willing to push themselves harder in the running session. In fact, all athletes do clearly take advantage (only in terms of $\mathrm{VO}_{2}$ and HR values) of the drafting situation during the bike leg of their triathlon, but this advantage seems to be higher in the athletes having a running profile/background. A high level of expertise and experience allows them to optimize their triathlon run performance to a higher degree than athletes not showing equivalent running skills. $\mathrm{VO}_{2}$ and $\mathrm{HR}$ (Fig. 3, A and B) followed the same evolution as performance 
times: the higher the run speed, the higher $\mathrm{VO}_{2}$ and $\mathrm{HR}$. The higher expiratory flow (VE) values observed during TD run compared with TA run $\left(+21 \mathrm{~L}-\mathrm{min}^{-1}\right)$ may be partly explained by the respective $+5.3 \%$ increase in $\mathrm{VO}_{2}$ stemming from an enhanced oxygen flow to the active muscles (4). Furthermore, Robertson et al. (27) suggested that as resistance increases, more energy is needed to generate sufficient tension in the muscles to obtain the pressures required for airflow to occur while some energy is also used to prevent deformation of the chest wall during increased work. Therefore, less energy is used to move air, suggesting that as air resistance increases that more mechanical energy is required to accomplish inspiration.

In conclusion, the present investigation constitutes the first scientific contribution to characterizing the impact of drafting during the bike leg of a triathlon on run performance Our results indicate that the legalization and standard use of drafting in triathlon races induces important physiological and biomechanical alterations that can impact performance. As we chose to reproduce the same bike speed and tempo for both draft and no-draft triathlon, the bike modalities constitute a clear limit to the present study. However, drafting will enable riders to conserve energy during the cycling phase of the competition and improve run phase by alternating the lead position with the rider off of whom they are drafting.

Finally, the high lactate values recorded at the end of the drafted triathlon may indicate that triathlon training should require more activation of glycolytic pathway, at least for short distance (sprint and classic) triathlons.

The authors gratefully acknowledge the European Triathlon Union, and the French and Finnish Triathlon Federations for their active support during the entire experiment.

C. Hausswirth, Ph.D., Institut National du Sport et de L'Education Physique, Laboratoire de Biomécanique et de Physiologie, 11, avenue du Tremblay, 75012 Paris, France.

\section{REFERENCES}

1. BERGMEYER, H. U. Methods of Enzymatic Analysis. New York: Academic Press, 1974.

2. BOGDANIS, G. C., M. E. NEVIIL, and H. H. K. LAKOMY. Effects of previous dynamic arm exercise on power output during repeated maximal sprint cycling. J. Appl. Physiol. 12:363-370, 1994.

3. BROOKS, J. D., and G. J. DAVIES. Comment on estimation of the EE of sporting cyclists. Ergonomics 16:237-238, 1973.

4. COAST, J. R., and K. M. KRAUSE. Relationship of oxygen consumption and cardiac output (CO) to work of breathing. Med. Sci. Sports Exerc. 25:335-340, 1993.

5. COYLE, E. F., L. S. SIDOSSIS, J. F. HoRowrrz, and J. D. BELTZ. Cycling efficiency is related to the percentage of type I muscle libers. Med. Sci. Sports Exerc. 24:782-788, 1992.

6. DAVIES, C. T. M. Effect of air resistance on the metabolic cost and performance of cycling. Eur. J. Appl. Physiol. 45:245-254, 1980.

7. DI PRAMPERO, P. E. The energy cost of human locomotion on land and in water. Int. J. Sports Med. 7:55-72, 1986.

8. GUEZENNEC, C. Y., J. M. VALLIER, A. X. BIGARD, and A. DUREY. Increase in energy cost of running at the end of a triathlon. Eur. J. Appl. Physiol. 73:440-445, 1996.

9. HAGBERG, J. M., and S. D. McCOLE. The effect of drafting and aerodynamic equipment on EE during cycling. Cycling Sci. 2:19 - 22, 1990.

10. HAGBERG, J. M., J. P. MULLIN, M. D. GIESE, and E. SPITZNAGEL. Effect of pedalling rate on submaximal exercise responses of competitive and recreational cyclists. J. Sports Med. 9:191-203, 1981.

11. HAUSSWIRTH, C., A. X. BIGARD, R. LEPERS, M. BERTHELOT, and C. Y. GUEZENNEC. Sodium citrate ingestion and muscle performance in acute hypobaric hypoxia. Eur. J. Appl. Physiol. 
71:362368, 1995.

12. HAUSSWIRTH, C., A. X. BIGARD, M. BERTHELOT, M. THOMAIDIS, and C. Y. GUEZENNEC. Variability in energy cost of running at the end of a triathlon and a marathon. Int. J. Sports Med. 17:574-581, 1996.

13. HAUSSWIRTH, C., BIGARD A. X., LECHEVALIER J. M. The Cosmed K4 telemetry system as an accurate device for oxygen uptake measurements during exercise. Int. J. Sports Med. 18:1-5, 1997, 1997.

14. HERMANSEN, L., and J. B. OSNES. Blood and muscle $\mathrm{pH}$ after maximal exercise in man. $J$. Appl. Physiol. 32:304-308, 1972.

15. KREIDER, R. B., D. E. CUNDIFF, J. B. HAMMET, C. W. CORTES, and K. W. WILLIAM. Effects of cycling on running performance in triathletes. Ann. Sports Med. 4:220-225, 1988.

16. KYLE, C. R. Reduction of wind resistance and power output of racing cyclists and runners travelling in groups. Ergonomics 22: 387-397, 1979.

17. McCOLE, S. D., K. CLANEY, J. C. CONTE, R. ANDERSON, and J. M. HAGBERG. EE during bicycling. J. Appl. Physiol. 68:748-753, 1990.

18. McMIKEN, D. F., and J. T. DANIELS. Aerobic requirements and maximum aerobic power in treadmill and track running. Med. Sci. Sports. 8:14-17, 1976.

19. MEDBO, J. I., MOHN A. C., TABATA I., BAHR R., VAAGE O., and SEJERSTED 0. M. Anaerobic capacity determined by maximal accumulated $0_{2}$ deficit. J. Appl. Physiol. 64:50-60, 1988.

20. MILNER-BROWN, H. S., and R. B. STEIN. The relation between the surface electromyogram and muscular force. $J$. Physiol. 246:549569, 1975.

21. 0' TOOLE, M. L., W. D. B. HILLER, L. 0. CROSBY, and P. S. DOUGLAS. The ultraendurance triathlete: a physiological profile. Med. Sci. Sports Exerc. 19:45-50, 1987.

22. PATTERSON, R. P., and M. I. MORENO. Bicycle pedalling forces as a function of pedalling rate and power output. Med. Sci. Sports Exerc. 22:512-516, 1990.

23. PETROFSKY, J. S., C. A. PHILIPS, M. N. SAWKA, D. HANPETER, and D. STAFFORD. Blood flow and metabolism during isometric contractions in cat skeletal muscle. J. Appl. Physiol. 50:493-502, 1981.

24. PUGH, L. G. C. E. Oxygen intake in track and treadmill running with observations on the effect of air resistance. J. Physiol. 207: 823-835, 1970.

25. PUGH, L. G. C. E. The effect of wind resistance in running and walking and the mechanical efficiency of work against horizontal and vertical forces. J. Physiol. Lond. 213:255-270, 1971.

26. PUGH, L. G. C. E. The relation of oxygen intake and speed in competition cycling and comparative observations on the bicycle ergometer. J. Physiol. Lond. 213:255-270, 1974.

27. ROBERTSON, C. H., G. H. FOSTER, and R. L. JOHNSON. The relationship of respiratory failure to the oxygen consumption of, lactate production by, and the distribution of blood flow among respiratory muscles during increasing inspiratory resistance. J. Clin. Invest. 59:31-42, 1977.

28. RUNDELL, K. W. Effects of drafting during short-track speed skating. Med. Sci. Sports Exerc. 29:765-771, 1996.

29. SAHLIN, K. International Series on Sport Sciences, Biochem. Exerc. VI. Champaign, IL: 1986, pp. 323-343.

30. SANDERSON, D. J. The influence of cadence and power output on the biomechanics of force application during steady-rate cycling in competitive and recreational cyclists. J. Sports Med. 9:191203, 1991.

31. SPRIET, L. L., SODERLUND K., BERGSTROM M., and E. HULTMAN. Skeletal muscle glycogenolysis, glycolysis, and $\mathrm{pH}$ during electrical stimulation in men. J. Appl. Physiol. 62:616-621, 1987.

32. SWAIN, D. P., J. R. COAST, P. S. CLIFFORD, M. C. MILLIKEN, and J. STRAYGUNDERSON. Influence of body size on oxygen consumption during bicycling. J. Appl. Physiol. 62:668-672, 1987. 
33. TAKAISHI, T., Y. YASUDA, and T. MORITANI. Neuromuscular fatigue during prolonged pedaling exercise at different pedaling rates. Eur. J. Appl. Physiol. 69:154-158, 1994.

34. TRIVEDI, B., and W. H. DANFORTH. Effect of pH on the kinetics of frog muscle PFK. J. Biol. Chem. 241:4110-4114, 1966.

35. TROUP, J. P. The effect of drafting on training and performance capacity. Studies by the International Center for Aquatic Research. Colorado: U.S. Swimming Press, 1990.

36. VALLIER, J M., C. HAUSSWIRTH, J. BRISSWALTER, and F. BIGNET. Determination of the optimal pedalling rate in triathletes. Arch. Physiol. Biochem. 104:625, 1996.

FIGURES and TABLES

Figure 1 Protocol of experiment

ISOLATED 5K RUN (IR)

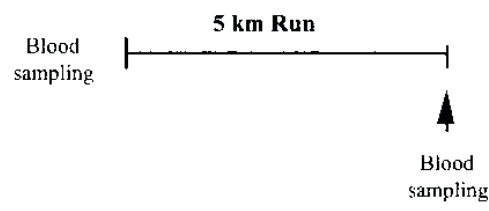

TRIATHLON ALONE (TA)

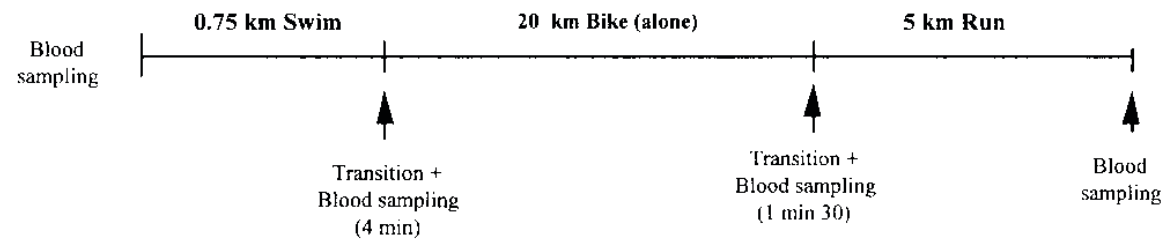

TRIATHLON DRAFT (TD)

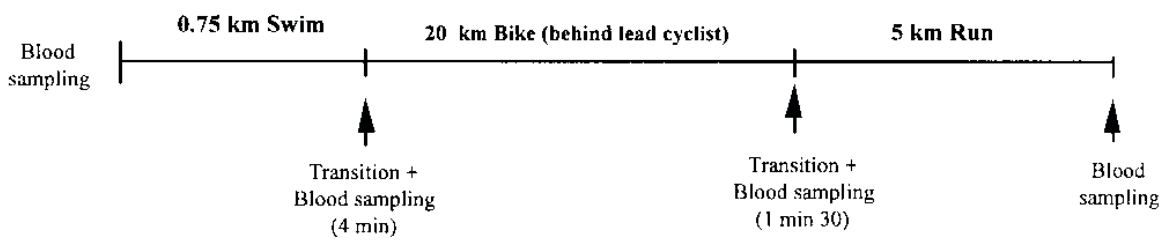


Figure 2-A, Changes in oxygen uptake values obtained during the bike section of drafted (TD) vs no-drafted (TA) triathlons. B, Changes in HR values obtained during the bike section of drafted (TD) vs no-drafted (TA) triathlons.

A

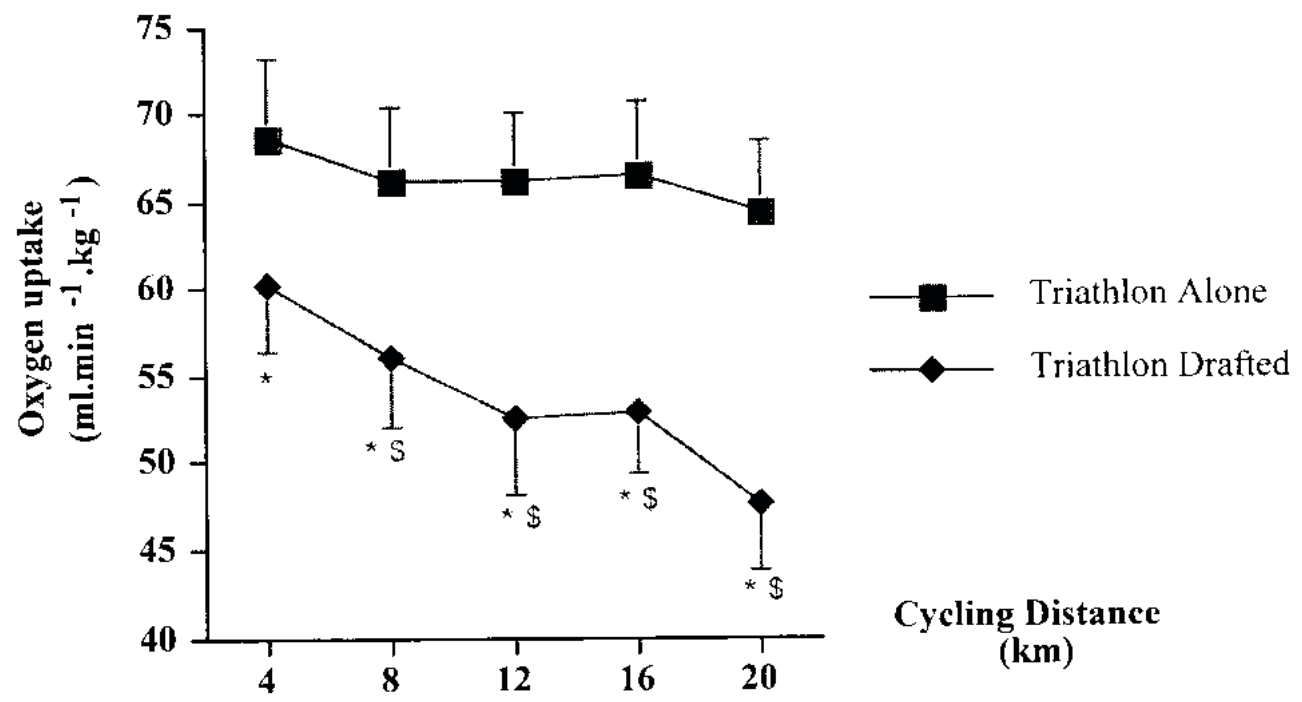

B

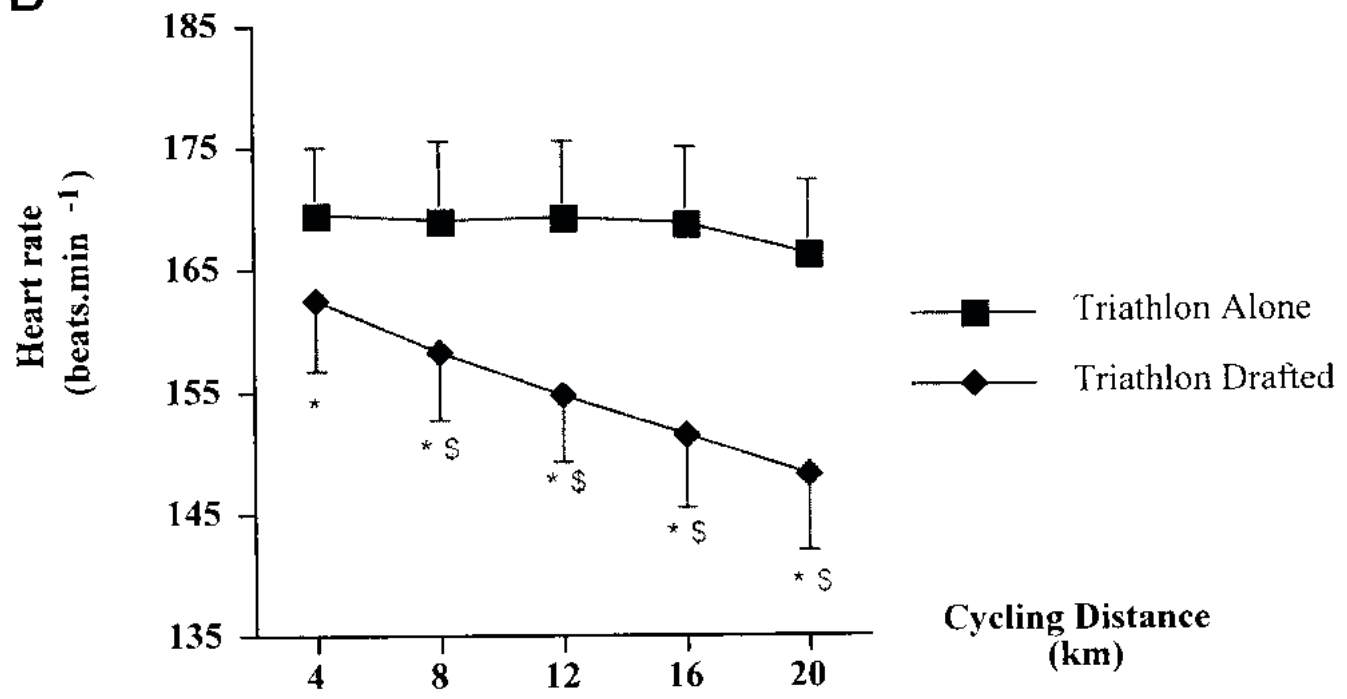


Figure 3-A, Changes in oxygen uptake values obtained during the run section of drafted (TD) vs no-drafted (TA) triathlons. B, Changes in HR values obtained during the run section of drafted (TD) vs no-drafted (TA) triathlons.

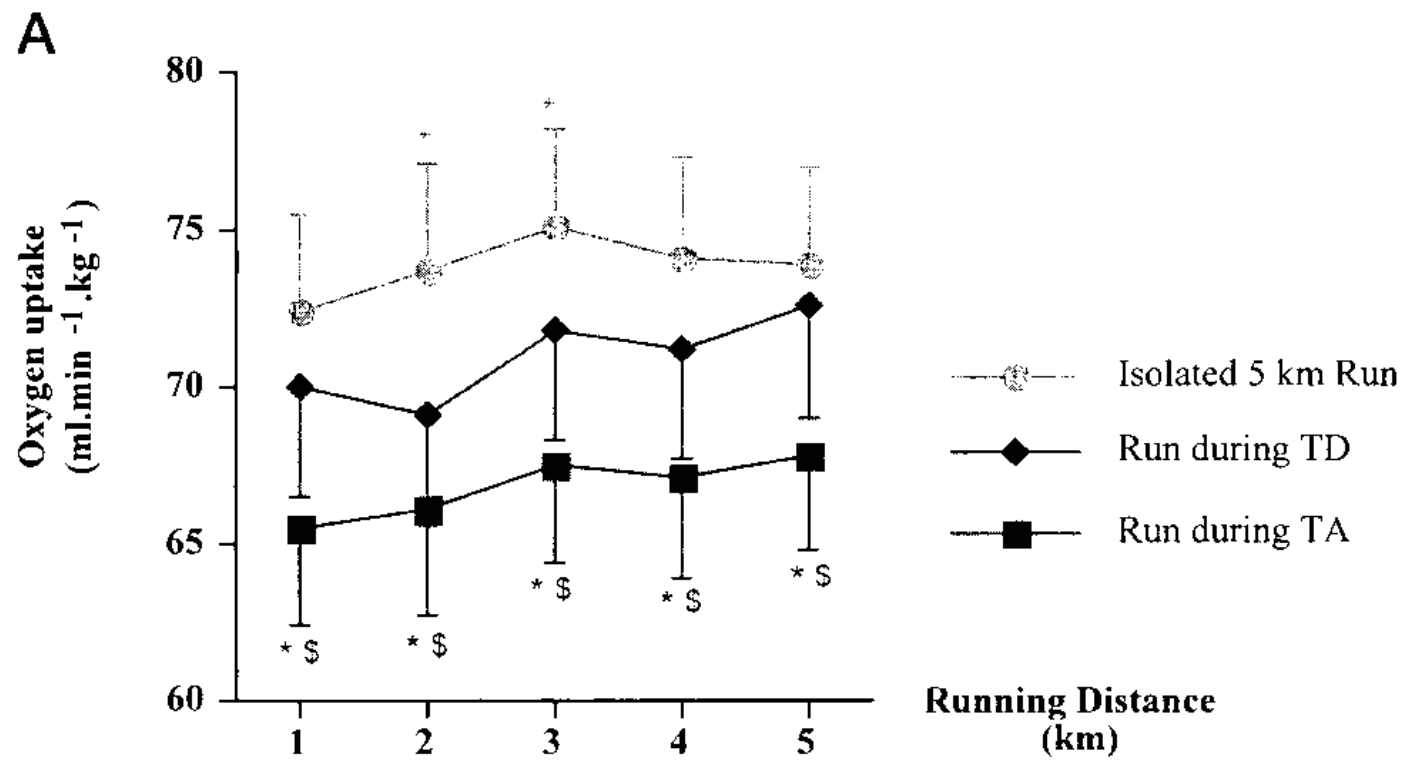

B

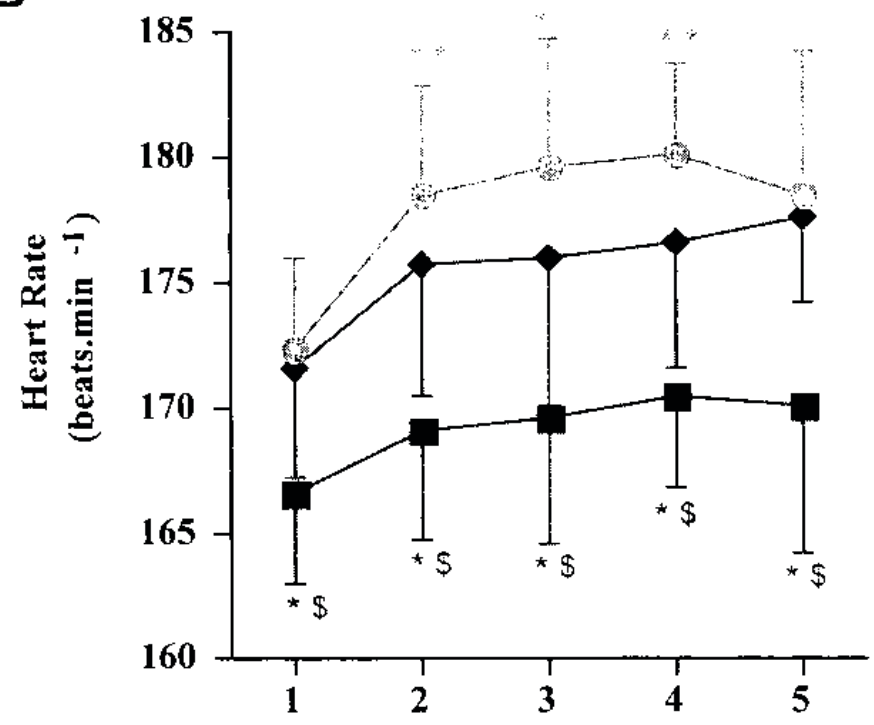

……........ Isolated $5 \mathrm{~km}$ Run

$\longrightarrow$ Run during TD

- Run during TA

Running Distance

(km) 
Figure 4 -Evolution of pedaling rate values during the triathlon atone (TA) and the triathlon drafted (TD). Values are means $( \pm \mathrm{SD})$.

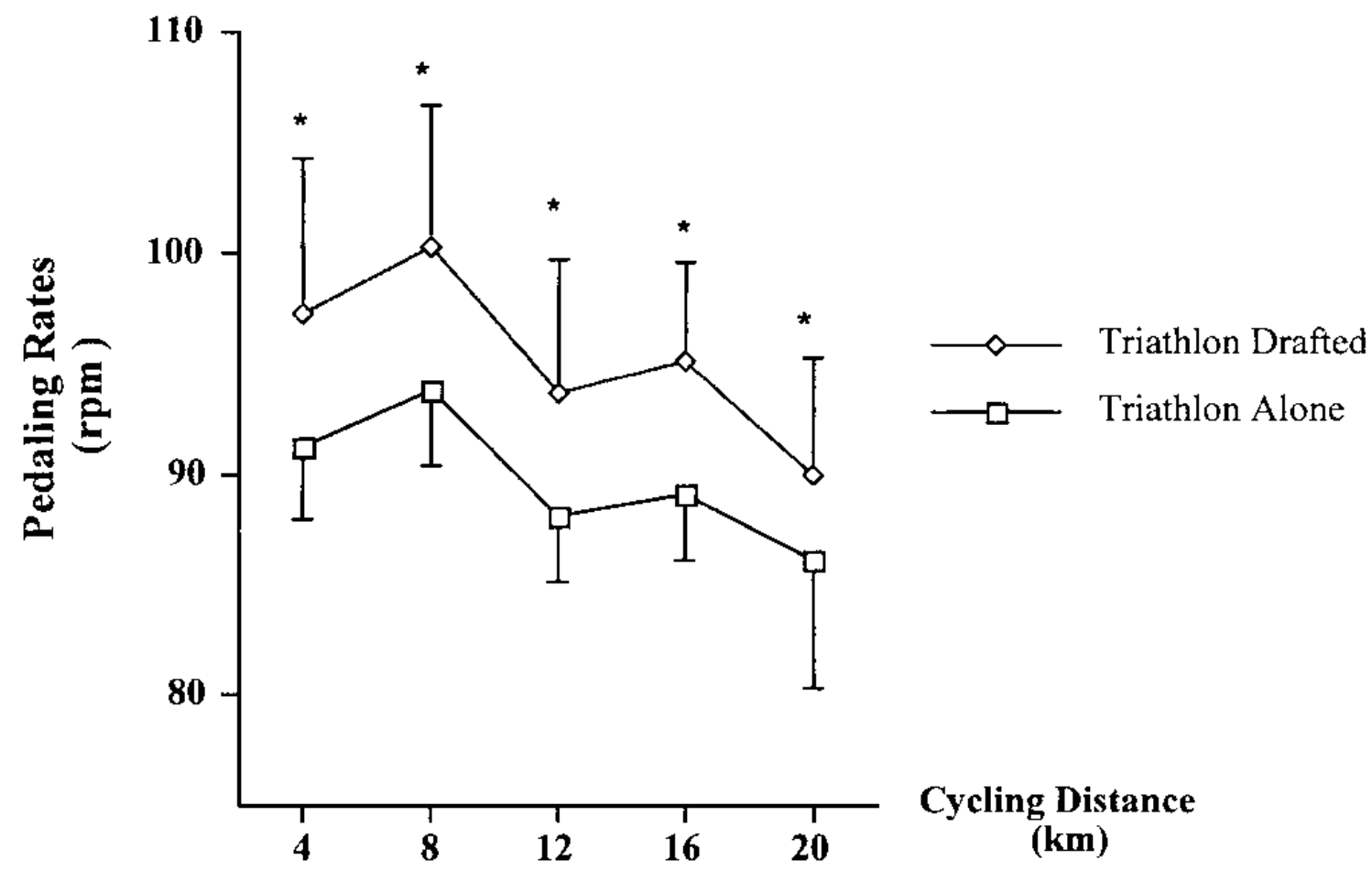

TABLE 1. Time performances obtained during each session; values are means $( \pm \mathrm{SD})$.

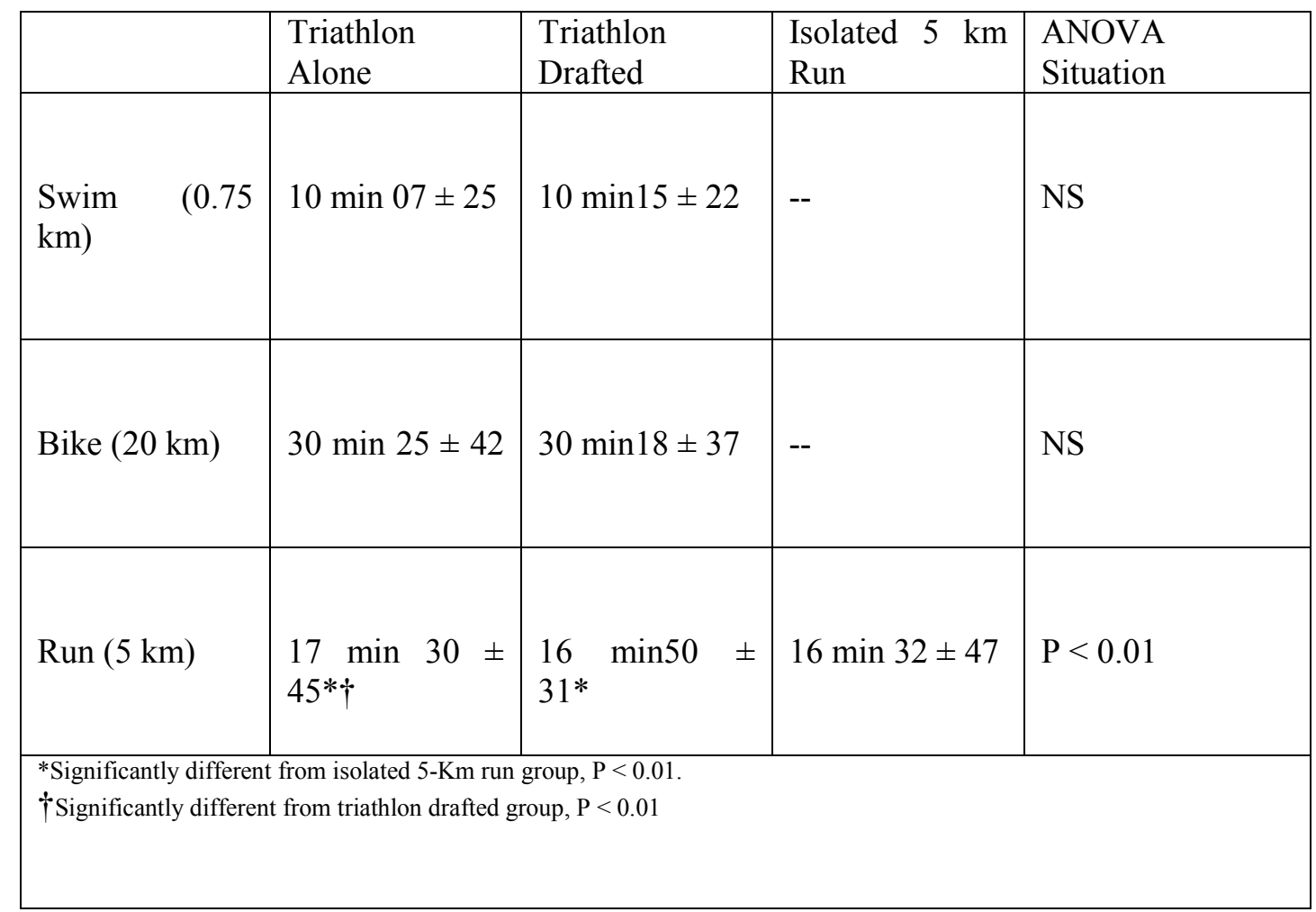


TABLE 2. Mean speed, oxygen uptake, expiratory flow, heart rate, and blood lactate concentration during the triathlon alone, the triathlon drafted, and the isolated 5-km run; Values are means $( \pm$ SD)

\begin{tabular}{|c|c|c|c|c|c|c|c|}
\hline Parameters & \multicolumn{2}{|c|}{ Triathlon Alone } & \multicolumn{2}{|c|}{ Triathlon Drafted } & \multicolumn{2}{|c|}{ Isolated $5 \mathrm{~K}$ run } & ANOVA \\
\hline & Bike & Run & Bike & Run & Bike & Run & \\
\hline Speed $\left(\mathrm{km} \bullet \mathrm{h}^{-1}\right)$. & $39.4 \pm 0.8$ & $17.1 \pm 0.6^{* \dagger}$ & $39.6 \pm 0.8$ & $17.8 \pm 0.5^{*}$ & & $18.2 \pm 0.4$ & $\mathrm{P}<0.01$ \\
\hline $\begin{array}{l}\text { Oxygen uptake } \\
(\mathrm{V} 02 ; \mathrm{ml} \bullet \mathrm{min}- \\
\left.1 \cdot \mathrm{kg}^{-1}\right)\end{array}$ & $\begin{array}{l}64.2 \pm \\
5.8 \dagger\end{array}$ & $67.1 \pm 5.1 * \dagger$ & $55.2 \pm 4.1$ & $70.9 \pm 6.0^{*}$ & & $74.1 \pm 5.2$ & $\mathrm{P}<0.01$ \\
\hline $\begin{array}{l}\text { Expiratory flow } \\
\left(\mathrm{VE} ; \mathrm{L} \cdot \mathrm{min}^{-1}\right)\end{array}$ & $\begin{array}{l}162.2 \pm \\
14.2 \dagger\end{array}$ & $\begin{array}{l}141.4 \pm \\
12.2 * \dagger\end{array}$ & $\begin{array}{l}112.1 \pm \\
9.1\end{array}$ & $\begin{array}{l}161.6 \pm \\
11.0^{*}\end{array}$ & & $\begin{array}{l}158.7 \pm \\
11.5\end{array}$ & $\mathrm{P}<0.01$ \\
\hline $\begin{array}{l}\text { Heart rate (HR; } \\
\left.\text { beats• } \min ^{-1}\right)\end{array}$ & $\begin{array}{l}166.8 \pm \\
11.2 \dagger\end{array}$ & $\begin{array}{l}167.9 \pm \\
14.2 \dagger\end{array}$ & $\begin{array}{l}155.0 \pm \\
10.1\end{array}$ & $\begin{array}{l}175.3 \pm \\
12.8^{*}\end{array}$ & & $\begin{array}{l}177.4 \pm \\
14.5\end{array}$ & $\mathrm{P}<0.01$ \\
\hline $\begin{array}{l}\text { Lactatemia, } \\
\left(\mathrm{mmol} \cdot \mathrm{L}^{-1}\right)\end{array}$ & $8.4 \pm 0.5 \dagger$ & $7.6 \pm 0.4$ & $4.0 \pm 0.3$ & $8.1 \pm 0.7^{*}$ & & $6.8 \pm 0.6$ & $\mathrm{P}<0.01$ \\
\hline
\end{tabular}

*Significantly different from isolated 5 -Km run group, $\mathrm{P}<0.01$.

$\dagger$ Significantly different from triathlon drafted group, $\mathrm{P}<0.01$. 